\title{
Computational program to evaluate local defects type Chalmers Test on a reflective optical surface
}

\section{Programa Computacional para evaluar defectos locales tipo Prueba de Chalmers en una superficie óptica reflectiva}

\author{
CANALES-PACHECO, Benito†*"', RUEDA-SORIANO, Esteban"”, RUIZ-AGUILAR, Luis Alberto" \\ and NORIEGA-LOREDO, Raymundo Sergio"
}

'Universidad Tecnológica de la Sierra Hidalguense, Information and Communication Technologies Department, Mexico.

"Cuerpo Académico UTSH-CA-6, Information Technology and Telecommunications, Mexico.

"' Universidad Autónoma del Estado de Hidalgo, Institute of Basic Sciences and Engineering, Mexico.

ID $1^{\text {st }}$ Author: Benito Canales Pacheco / ORC ID: 0000-0002-5396-2831, CVU CONACYT ID: 206767

ID $1^{\text {st }}$ Co-author: Esteban Rueda Soriano / ORC ID: 0000-0002-5430-2536, CVU CONACYT ID: 209823

ID $2^{\text {nd }}$ Co-author: Luis Alberto Ruiz, Aguilar / ORC ID: 0000-0002-6425-5665

ID $3^{\text {rd }}$ Co-author: Raymundo Sergio Noriega Loredo / ORC ID: 0000-0002-4751-2658, CVU CONACYT ID: 621009

DOI: $10.35429 /$ JSTA.2021.19.7.18.24

Received January 20, 2021; Acceptance June 30, 2021

\begin{abstract}
A computational tool is developed to measure the local deformations in optical surfaces from the interference patterns obtained by the Chalmers test principle and from the analysis of a reflective optical surface using a commercial Fizeau interferometer of the ZYGO. The tests were made on a concave spherical mirror with a radius of curvature of $60 \mathrm{~cm}$ and a diameter of $13 \mathrm{~cm}$. To obtain the measurements of local deformations, a computational tool proposed for the localization of dark fringes is used by evaluating the maximum and minimum of the image obtained in the interference patterns. The results obtained show that the computational tool allows locating fringes within an interference pattern, allowing faster inter-fringe measurements and assigning an error on the surface in terms of wavelength.
\end{abstract}

Interferogram analysis, Chalmer's test, Young's experiment, Optical tests, Reflective spatial light modulator, Reflective spatial light modulator

\section{Resumen}

Se desarrolla una herramienta computacional que permite medir las deformaciones locales en superficies ópticas a partir de los patrones de interferencia obtenidos por el principio de la prueba de Chalmers y del análisis de una superficie óptica reflectiva utilizando un interferómetro comercial de Fizeau de la marca ZYGO ${ }^{\mathrm{TM}}$. Las pruebas se realizaron sobre un espejo esférico cóncavo con radio de curvatura de $60 \mathrm{~cm}$ y diámetro de $13 \mathrm{~cm}$. Para obtener las mediciones de las deformaciones locales, se usa una herramienta computacional propuesta para la localización de franjas obscuras mediante la evaluación de máximos y mínimos de la imagen, obtenida en los patrones de interferencia. Los resultados obtenidos muestran que la herramienta computacional permite localizar las franjas dentro de un patrón de interferencia, permitiendo de una forma más rápida las mediciones entre franjas y asignar un error en la superficie en términos de la longitud de onda.

Análisis de interferogramas, Prueba de Chalmers, Experimento de Young, Pruebas ópticas, Modulador espacial de luz reflectivo

Citation: CANALES-PACHECO, Benito, RUEDA-SORIANO, Esteban, RUIZ-AGUILAR, Luis Alberto and NORIEGALOREDO, Raymundo Sergio. Computational program to evaluate local defects type Chalmers Test on a reflective optical surface. Journal of Scientific and Technical Applications. 2021. 7-19:18-24.

\footnotetext{
* Correspondence to Author (Email: arcastillor@gmaill.com)

$\uparrow$ Researcher contributing as first author.
} 


\section{Introduction}

In optics workshops, different test techniques are used for the measurement of optical surfaces, such as Ronchi, Hartman, Fizeau and Newton, as mentioned by (Malacara, 1999), among others. Most of these tests perform global measurements on the surfaces, there are other tests that determine measurements in specific locations, and these tests are usually difficult to perform so their use is limited. One of these techniques is the Chalmers test described by (Martin, 1959), where he evaluates the local deformations of a biconvex lens, using an extended light source that is placed at a distance of $2 f$ from the lens under test, then a screen called Chalmers is placed in the exit pupil of the lens, which contains a set of holes that are perpendicular to the optical axis forming a line, two holes are manually selected with the help of a selector template so that it covers the remaining ones, letting the light pass only in the selected holes, these act as two secondary light sources that are propagated and superimposed at a distance $2 f$ posterior to the lens, where a pattern of inference fringes can be observed.

In particular, the Chalmers test has had several modifications as expressed by (Zuloaga, 1994), where the same principle is used, the significant difference is in the screen called Chalmers, the author uses the lithography technique to improve the distribution of the holes of the screen while retaining the idea of the original proposal. A recent work is presented by the authors (Canales Pacheco, Cornejo Rodríguez, \& Granados Agustin, Chalmers Interferometric Test Using a Reflective Spatial Light Modulator, 2012), where they retain the principle of the test to analyze the local defects of a concave spherical mirror. The proposed technique is based on using a Reflective Spatial Light Modulator (RSLM), to simulate a Chalmer screen, this is possible by projecting two holes on the optical modulator using a computer. The use of this device provides a flexible way to select two holes from a particular area of the mirror to be dynamically tested, instead of using a rigid screen as traditionally done. The main advantage in this work is the way to select a pair of holes to perform the test in real time, for any area, with different sizes and orientation of the holes, the latter being of great importance to select the optimum size and distance between them.
This work describes a computational algorithm that allows to evaluate the maximum profiles of the image of an interferogram with local deformations, a similar work is presented by (Canales Pacheco, Toto Arellano, \& Austria González, Analysis of the local defects of a concave spherical surface using three measurement techniques, 2018), the authors use the commercial interferometry software DURANGO $^{\mathrm{TM}}$ (Diffraction, 2014), which is based on the algorithms of (Hariharan, 1987), which according to his theory; is a method of temporal phase changes that is analyzed from the resulting intensity pattern, likewise it is mentioned that they use a commercial Fizeau type interferometer of the $\mathrm{ZYGO}^{\mathrm{TM}}$ brand and in the exit pupil of this instrument a piezoelectric transducer is placed, which allows to perform phase changes. It is possible to record 9 interferograms, each one displaced with a phase difference of $\pi / 4$ and using the commercial software, the wavefront of the mirror under test is reconstructed, where the local deformations of the mirror in terms of wavelengths are obtained.

\section{Proposal of a Computational Algorithm for the analysis of an Interferogram with local deformations}

There are several commercial computational methods that analyze interferograms to determine deformations contained in an optical surface, however most of them fail to quantify local deformations, generally they obtain an average value of the whole interferogram. Therefore, this paper describes the development of a computational algorithm that allows measuring local errors in a concave spherical mirror in terms of wavelength, from analyzing a corresponding interferogram as explained by the authors (Canales Pacheco, Cornejo Rodríguez, \& Granados Agustin, Chalmers Interferometric Test Using a Reflective Spatial Light Modulator, 2012). For the development of the algorithm and explanation of the proposal, the four phases shown in Figure 1 are used, it is very important to mention that the first two are explained in more detail in the works already mentioned by (Canales Pacheco, Cornejo Rodríguez, \& Granados Agustin, Chalmers Interferometric Test Using a Reflective Spatial Light Modulator, 2012) and (Canales Pacheco, Toto Arellano, \& Austria González, Analysis of the local defects of a concave spherical surface using three measurement techniques, 2018). 


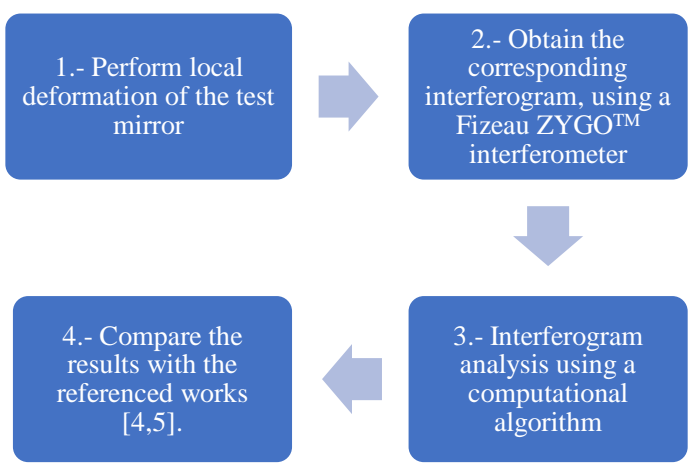

Figure 1 Proposed methodology to analyze the local deformations of an interferogram

1. Local deformation of a mirror: The optical test is performed on a concave spherical mirror with a radius of curvature of $60 \mathrm{~cm}$ and a diameter of $13 \mathrm{~cm}$. The newly constructed mirror has an optical quality that meets the specifications established by the optics workshop "Alejandro S. Cornejo Rodriguez" of the National Institute of Astrophysics, Optics and Electronics (INAOE) where it was manufactured. To generate the local deformations in the test mirror, the optics workshop technician uses a mirrorpolishing piece to manually generate random deformations on the surface. Figure 2a) shows the test mirror and on it, the polishing piece that makes physical contact causing considerable damage to the test surface.

2. Obtain an interferogram of the test mirror: In the work of (Canales Pacheco, Cornejo Rodríguez, \& Granados Agustin, Chalmers Interferometric Test Using a Reflective Spatial Light Modulator, 2012), they describe that with a commercial Fizeau interferometer of the ZYGOTM brand provided by INAOE, the mirror under test is analyzed and an interferogram is obtained as shown in figure $2 \mathrm{~b}$ ); where it is clearly observed that the interferogram contains localized distortion fringes, mainly in the center and the superior part. It is also observed that there are areas where the fringes are kept straight and parallel, this region is very important for this proposal, on the other hand it is known from the scientific literature; that if the mirror is free of damage or aberrations, it is expected to obtain an interferogram with straight, parallel and equally spaced fringes, otherwise distorted fringes are observed, as it is in this case that local damages were generated.
June 2021, Vol. 7 No.19 18-24

a)
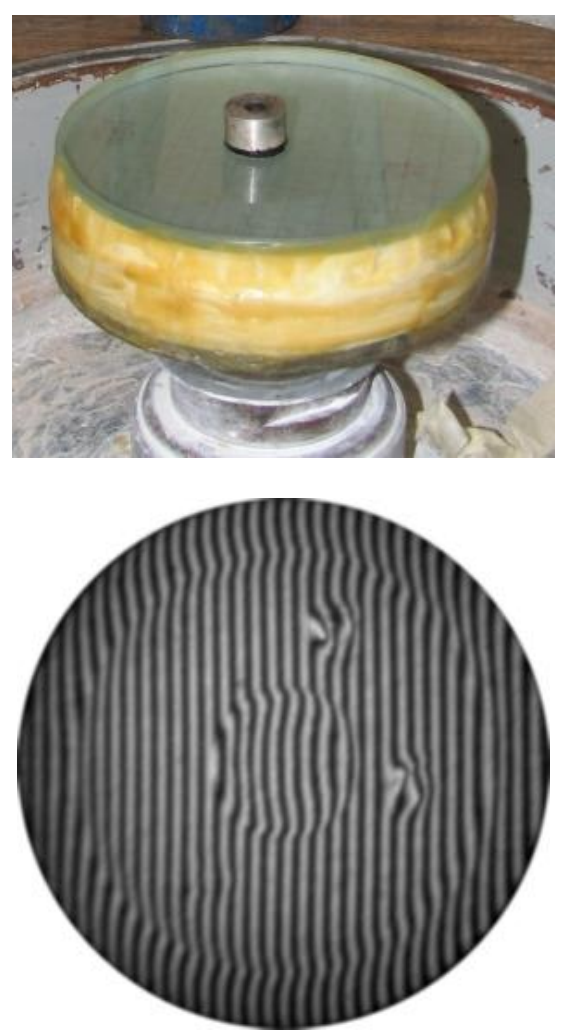

b)

Figure 2 a) Deformations caused to the test mirror b) Interferogram obtained from the ZYGOTM commercial interferometer

3. Analysis of the interferogram using a
computational algorithm: The computational algorithm is developed in Matlab and with the use of matrix arrays the pixels of the interferogram image shown in figure 2b) are identified. First, the program declares the input variables that will allow reading the interferogram image in bmp format; this is possible with the following instruction.

clear all

close all

clc

num1=input('Insert image:','s');

I = imread(num1);

$[\mathrm{i}, \mathrm{j}]=\operatorname{size}(\mathrm{I})$;

Second, the conditions for locating the dark fringe of the interferogram image in the vertical and horizontal direction are set to perform the reading of the image in gray level; the following code is used to make this possible. 


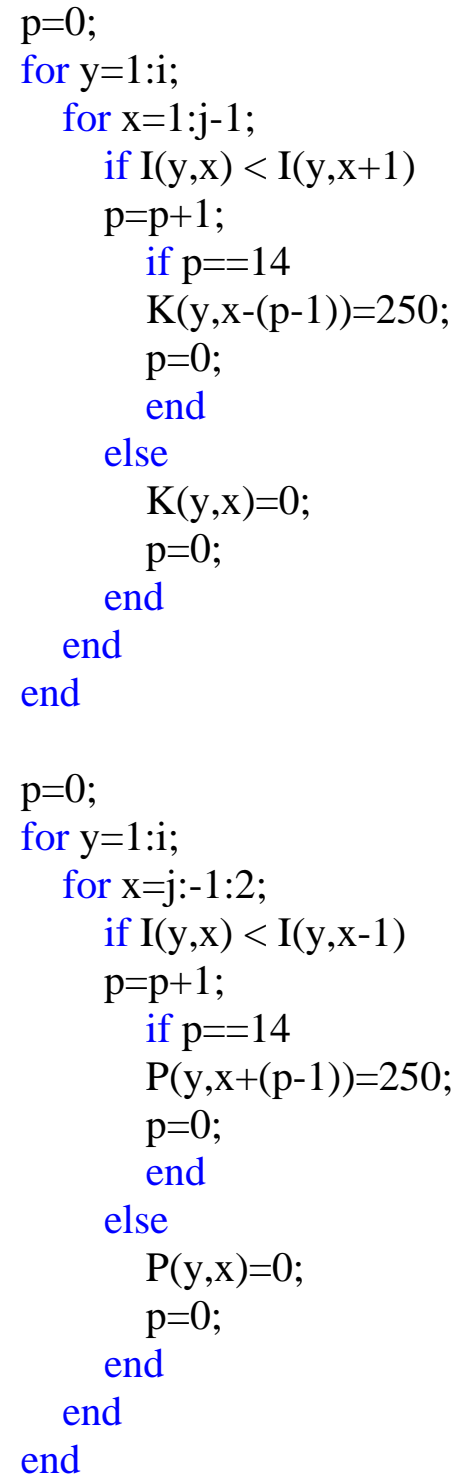

Third, input variable declarations are made in the $(\mathrm{x}, \mathrm{y})$ direction that allow inserting the position from 0 to 1400 pixels and corresponds to the position of the profile to be plotted within the interferogram, using the following syntax.

$[i, j]=\operatorname{size}(K)$;

$\mathrm{X}=1: \mathrm{j}$;

$\mathrm{Y}=\mathrm{i} / 2$;

$\mathrm{X}=[1, \mathrm{j}]$;

$\mathrm{y}=[500,500] ; \%$ Coordinates for plotting the profile of interest

[xcx,xcy, $\mathrm{xdatos}]=$ improfile $(\mathrm{K}, \mathrm{x}, \mathrm{y}, \mathrm{j})$;

$[\mathrm{cx}, \mathrm{cy}$, datos] $=$ improfile $(\mathrm{I}, \mathrm{x}, \mathrm{y}, \mathrm{j})$;

$\mathrm{xdatosinv}=250$ - $\mathrm{xdatos}$;

datosinv=250-datos;

It is also possible to plot the behavior of the stripes corresponding to the profile mentioned above, also plotting the position of each dark stripe, this is achieved by performing a sweep as follows: $[\mathrm{xcx}, \mathrm{xcy}, \mathrm{xXdatos}]=$ improfile $(\mathrm{P}, \mathrm{x}, \mathrm{y}, \mathrm{j})$;

$\mathrm{xXdatosinv}=250-\mathrm{x} X$ datos;

figure;

imshow(I)

hold on

$\mathrm{p}=\mathrm{plot}($ datosinv $)$;

set(p,'Color','red')\% Graph showing the behavior of the light and dark fringe xlabel('Pixels en $\mathrm{X}^{\prime}$ ); ylabel('Pixels en Y');

$\mathrm{pp}=\mathrm{plot}(\mathrm{x}, \mathrm{y})$;

set(pp,'Color','white')\% Profile selected in the interferogram

$\mathrm{ppp}=\operatorname{plot}(\mathrm{xXdatosinv})$

set(ppp,'color','green');\% Plot showing the position of the dark fringe

hold off

Figure 3 shows the interferogram under test, where a sinusoidal graph representing the distribution of light and dark stripes is observed. It also shows a green graph that indicates the position of each dark fringe and finally the white line that represents the profile under analysis. The number of detected fringes will depend on the area of the interferogram being selected.

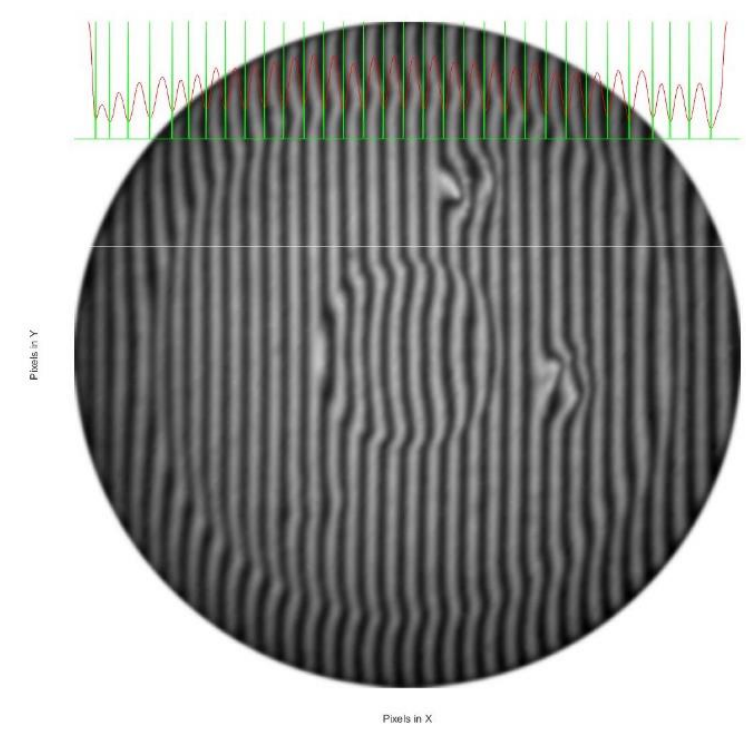

Figure 3 Interference fringes behavior corresponding to a specific interferogram profile

In this algorithm proposal it is possible to identify the position of each dark stripe, for this purpose the following code is used and its corresponding graph is shown in figure 4 , where it can be seen that the separation between strips is almost constant, except at the edges where it can be visually identified that the strips are distorted. 
figure;

hold on

$\mathrm{ppp}=\operatorname{plot}($ datos $)$;

set(ppp,'Color','red');

xlabel('Pixels');

ylabel('Gray levels');

$\% \mathrm{pp}=\operatorname{plot}(\mathrm{xdatosinv})$;

$\%$ set(pp,'Color','blue');

$\mathrm{ppp}=\mathrm{plot}(\mathrm{x} X$ datosinv $)$;

set(ppp,'Color','green');

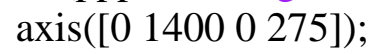

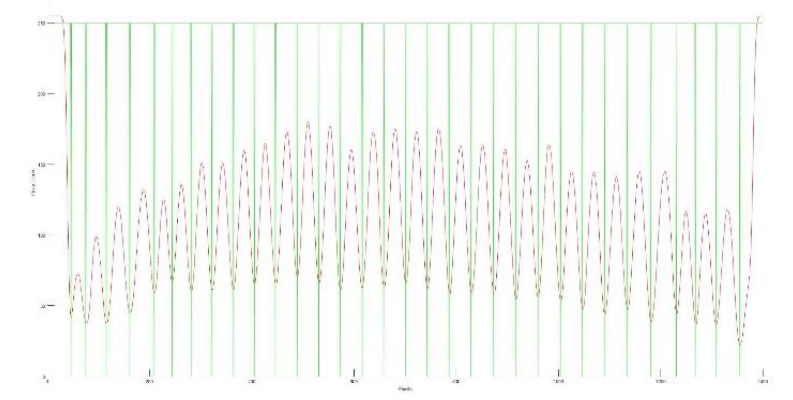

Figure 4 Location of the dark stripes in terms of pixels on the $\mathrm{x}$-axis

It is important to remember that the main objective of the proposal is to measure the error of the optical surface by finding the separation between two dark fringes of the interferogram. For this purpose, several zones of the interferogram are chosen that present a quasiconstant distribution in the period of the fringes, i.e. the region where straight and parallel fringes are observed, as shown in figure 4.

In this zone, the position of the dark fringe is identified by associating it with the corresponding pixel and a sweep is made over the profile, in such a way that it is possible to know the separation between them and subsequently calculate an average value. The value obtained is considered constant and is taken as reference $S$ or also considered as an ideal separation between two dark fringes. To know the displacement of a distorted fringe $\Delta S$ the procedure is similar; a profile is drawn in such a way that it crosses a zone of the interferogram with local deformation and then the position of the fringe of interest is known, then the difference between the position of the distorted fringe and $\boldsymbol{S}$ is obtained, thus knowing the displacement of the fringe $\Delta S$.
To calculate the error of the surface corresponding to the area where there are distorted fringes, we start from the fringe analysis theory, where it is known that if the interference pattern originated from the superposition of two waves as is the case in this study, then the distance between two consecutive dark or bright fringes is $\boldsymbol{\lambda} / \mathbf{2}$. Finally as a first approximation, the algorithm performs a quantitative analysis that allows to know the deviations of the localized fringes of the interferogram, using the equation of ((Guenther \& Liebengerg, 1978), assigned an error which is given by;

Surface error $=E s=\frac{\Delta s\left(\frac{\lambda}{2}\right)}{s}$

Where $\Delta \mathbf{S}$ is the deviation of a fringe and $\mathbf{S}$ is the separation between two consecutive experimental fringes, $\lambda$ is the wavelength of 633 nanometers.

\section{Results}

With the computer program developed by the authors, it is possible to know the behavior of the fringes in any profile of the interferogram, including the ability to plot an inclined profile as shown in Figure 5.

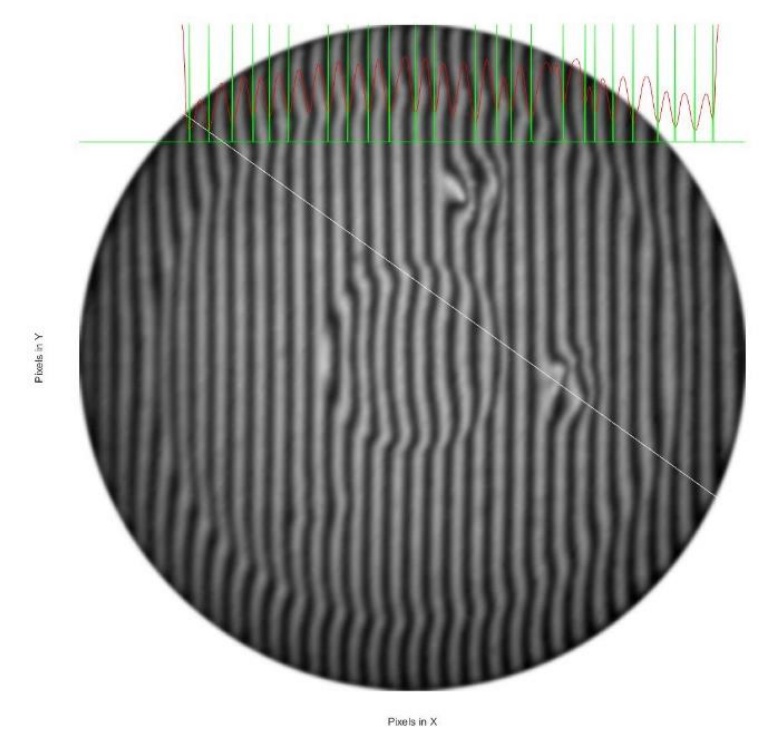

Figure 5 Behavior of the interference fringes corresponding to an inclined profile 
As an example of calculating the surface error in a local zone of the test mirror, 4 zones are selected from the interferogram identified as; A, B, C and D as shown in figure 6 , where it can be observed at a glance that they contain distorted fringes, due to the fact that the test mirror contains local damage as mentioned in point 1 of the methodology.

These same zones were analyzed in the work of B. Canales, where they use a Special Light Modulator for Reflection and in the work of Benito where they use the DURANGO software that allows the analysis of interferograms.

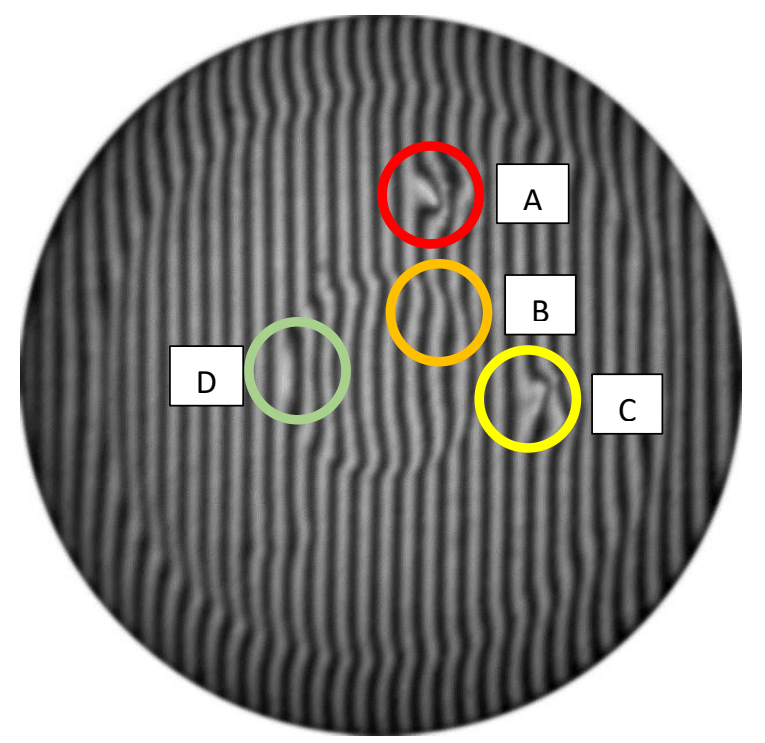

Figure 6 Behavior of interference fringes corresponding to an inclined profile

Table 1 shows the results obtained from the different proposals cited in this document, in particular in column 1 the analysis area is indicated and corresponds to the same for the three methods, column 2 shows the surface error value, using a reflective light spatial modulator as a simulator of the Chalmers screen, column 3 shows the results using the Commercial Fringe Analysis Software. Finally in column 4 the results using the method proposed here, of using a computational algorithm to measure local deformations of an interferogram and assign a surface error in terms of wavelength from equation 1 , it should be clarified that the same areas of the interferogram were analyzed for comparison.

\begin{tabular}{|l|l|l|l|}
\hline \multicolumn{4}{|c|}{ Surface error } \\
\hline Zone & $\begin{array}{l}\text { Using a } \\
\text { Special Light } \\
\text { Modulator } \\
\text { by } \\
\text { Reflection }\end{array}$ & $\begin{array}{l}\text { Using } \\
\text { Durango, } \\
\text { Interferometry } \\
\text { Software }\end{array}$ & $\begin{array}{l}\text { Proposed } \\
\text { algorithm in } \\
\text { MATLAB }\end{array}$ \\
\hline A & $0.51 \lambda$ & $0.49 \lambda$ & $0.50 \lambda$ \\
\hline B & $0.30 \lambda$ & $0.30 \lambda$ & $0.31 \lambda$ \\
\hline C & $0.44 \lambda$ & $0.45 \lambda$ & $0.44 \lambda$ \\
\hline D & $0.27 \lambda$ & $0.28 \lambda$ & $0.28 \lambda$ \\
\hline
\end{tabular}

Table 1 Comparison of results in the evaluation of local zones of the interferogram

Table 2, shows the difference between the error assigned with the described proposal and the results published in the aforementioned works (Canales Pacheco, Cornejo Rodríguez, \& Granados Agustin, Chalmers Interferometric Test Using a Reflective Spatial Light Modulator, 2012) and (Canales Pacheco, Toto Arellano, \& Austria González, Analysis of the local defects of a concave spherical surface using three measurement techniques, 2018), where it can be observed that there is a variation of $0.1 \lambda$.

\begin{tabular}{|c|c|c|}
\hline \multicolumn{3}{|c|}{ Difference in surface error } \\
\hline Zone & $\begin{array}{l}\text { Using a Special Light } \\
\text { Modulator by } \\
\text { Reflection }\end{array}$ & $\begin{array}{l}\text { Using Durango, } \\
\text { Interferometry } \\
\text { Software }\end{array}$ \\
\hline A & $0.1 \lambda$ & $0.1 \lambda$ \\
\hline $\mathrm{B}$ & $0.1 \lambda$ & $0.1 \lambda$ \\
\hline $\mathrm{C}$ & $0 \lambda$ & $0.1 \lambda$ \\
\hline $\mathrm{D}$ & $0.1 \lambda$ & $0 \lambda$ \\
\hline
\end{tabular}

Table 2 Difference in the error assigned to the local deformations of the mirror under test

\section{Conclusions}

With the development of the computational algorithm, a proposal for interferogram analysis has emerged that is considered economical because it does not require specialized laboratory equipment to measure local errors of an optical surface.

The results obtained are supported by the works presented by (Canales Pacheco, Cornejo Rodríguez, \& Granados Agustin, Chalmers Interferometric Test Using a Reflective Spatial Light Modulator, 2012) and (Canales Pacheco, Toto Arellano, \& Austria González, Analysis of the local defects of a concave spherical surface using three measurement techniques, 2018), which analyzed the same interferogram as mentioned in results. 
With the results shown in Table 1, it can be interpreted that the proposal presented can analyze surface errors of $0.01 \lambda$, equivalent to an optical quality of $\lambda / 80$ The results obtained were similar, which allows the described proposal to be reliable.

\section{References}

Canales Pacheco, B., Cornejo Rodríguez, A., \& Granados Agustin, F. (2012). Chalmers Interferometric Test Using a Reflective Spatial Light Modulator. Optics Express, 23865-23874.

Canales Pacheco, B., Toto Arellano, N. I., \& Austria González, L. F. (2018). Analysis of the local defects of a concave spherical surface using three measurement techniques. Interferometry XIX, 7.

Diffraction. (2014, Diciembre 9). Durango, Interferometry Software. Retrieved from http://www.diffraction.com/durango_software.p hp

Guenther, \& Liebengerg. (1978). Optical Interferograms Reduction and Interpretation. Philadelphia: ASTM.

Hariharan, P. (1987). Digital phase-shifting interferometry: a simple error-compensating phase calculation algorithmo. Applied Optics, 2504-2506.

Malacara, D. (1999). Optical Shop Testing. New York: John Wiley \& Sons.

Martin. (1959). Technical Optics. London: Pitman.

Zuloaga, M. A. (1994). Prueba de Chalmer's. Puebla: INAOE. 